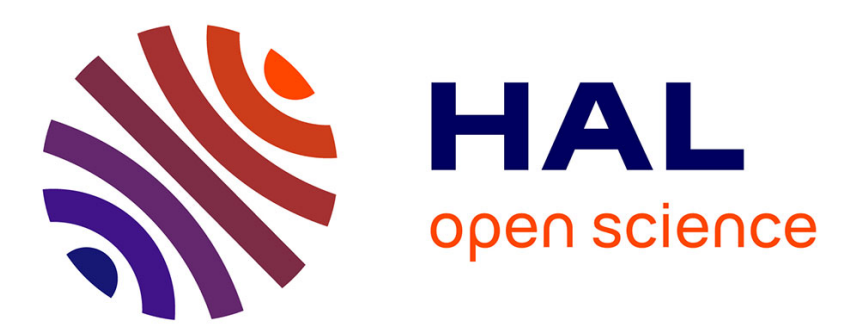

\title{
Global Model for Self-discharge and Capacity Fade in Lithium-ion Batteries Based on the Generalized Eyring Relationship
}

\author{
Eduardo Redondo-Iglesias, Pascal Venet, Serge Pelissier
}

\section{To cite this version:}

Eduardo Redondo-Iglesias, Pascal Venet, Serge Pelissier. Global Model for Self-discharge and Capacity Fade in Lithium-ion Batteries Based on the Generalized Eyring Relationship. IEEE Transactions on Vehicular Technology, 2018, pp. 104-113. 10.1109/TVT.2017.2751218 . hal-01593047

\section{HAL Id: hal-01593047 \\ https://hal.science/hal-01593047}

Submitted on 25 Sep 2017

HAL is a multi-disciplinary open access archive for the deposit and dissemination of scientific research documents, whether they are published or not. The documents may come from teaching and research institutions in France or abroad, or from public or private research centers.
L'archive ouverte pluridisciplinaire HAL, est destinée au dépôt et à la diffusion de documents scientifiques de niveau recherche, publiés ou non, émanant des établissements d'enseignement et de recherche français ou étrangers, des laboratoires publics ou privés. 


\title{
Global Model for Self-discharge and Capacity Fade in Lithium-ion Batteries Based on the Generalized Eyring Relationship
}

\author{
Eduardo Redondo-Iglesias, Pascal Venet, Serge Pelissier
}

\begin{abstract}
In this paper we present an innovative and precise way to calculate the available capacity in a battery. This quantity is essential to assess the ageing process during real use or ageing tests. Classical methods for measuring the available capacity in a battery are very dependent of impedance and relaxation state of the battery. Consequently, these methods are not suitable to quantify reversible and irreversible capacity losses occurring on batteries. We propose an indirect measure of available capacity that reduces the distortion caused by battery relaxation and impedance changes.

This new method provides more accurate results allowing to distinguish reversible from irreversible part of capacity losses. The obtained results on calendar ageing tests are used in a second part to model both self-discharge and capacity fade in a global approach by using the generalized Eyring relationship.
\end{abstract}

Keywords - Lithium-ion batteries, capacity losses, capacity fade, self-discharge, generalized Eyring relationship.

\section{ABBREVIATIONS}

$\begin{array}{ll}\text { CC } & \text { Constant Current } \\ \text { CE } & \text { Coulombic Efficiency } \\ \text { CP } & \text { Constant Power } \\ \text { CV } & \text { Constant Voltage } \\ \text { EoC } & \text { End of Charge } \\ \text { EoD } & \text { End of Discharge } \\ \text { RPT } & \text { Reference Performance Test }\end{array}$

\section{INTRODUCTION}

Battery is probably the most sensitive element in the Battery Electric Vehicle powertrain system because of their cost and lifespan. To study its lifespan, accelerated ageing tests are necessary in order to understand the ageing mechanisms in batteries and the performance evolution whithin this Energy Storage System.

Battery performances change due to parasitic reactions even during rest periods: internal impedance will grow and capacity decay. Capacity losses can be reversible or irreversible.

Copyright @2017 IEEE. Personal use of this material is permitted. However, permission to use this material for any other purposes must be obtained from the IEEE by sending a request to pubs-permissions@ieee.org.

E. Redondo-Iglesias and S. Pelissier are with the Transport and Environment Laboratory, French Institut of Science and Technology for Transport, Developpement and Networks (IFSTTAR/LTE), 69500, Bron, France (e-mail: eduardo.redondo@ifsttar.fr).

E. Redondo-Iglesias and P. Venet are with Ampere Laboratory, University of Lyon, UCB Lyon1, 69100, Villeurbanne, France.

All authors are with ERC GEST, France.
Reversible capacity loss is known as self-discharge whereas irreversible losses are known as capacity fade.

The aim of this paper is to provide an accurate way to measure capacity losses to be able to distinguish self-discharge and capacity fade of batteries.

When a battery is stored at a determined $S o C$, after a period of time, this value of $S o C$ decreases for two reasons: self-discharge and capacity fade. The issue is to separate the contribution of each phenomenon. When the reversible and irreversible losses are coupled, data collected in ageing tests could be largely inaccurate.

The main ageing mechanism in lithium-ion batteries is SEI formation [1], [2]. The mechanism is responsible for both capacity fade and impedance rise. Impedance rise can cause a distortion on the available capacity measurement and then in the assessment of self-discharge.

Yazami and Reynier [3], [4] suggested that the selfdischarge phenomenon lies on the formation of an intermediary substance: an electron-ion - solvent complex. This intermediary substance can react in two ways: the first one is to form SEI layer that leads to irreversible capacity loss. The second possible reaction takes places during a subsequent cell charge: the complex can partially dissociate and lithium can re-intercalate into the negative electrode.

There are several ways to measure self-discharge on batteries. The indirect method is based on the cell voltage monitoring when in rest condition. This method can be satisfactory on supercapacitors [5] but it is not appropriated for high accuracy self-discharge measurements in lithium-ion cells. In fact, very slow phenomena (relaxation) occur inside lithiumion cells affecting the cell voltage. Moreover, this method requires to transform the voltage evolution to capacity loss by the means of the $\mathrm{OCV}(S o C)$ relation [6]. This transform involves inaccuracy because $\mathrm{OCV}(\mathrm{SoC})$ relation can evolve over time.

Direct methods for measuring self-discharge consist in discharging or charging the cell to a predetermined $S o C$ [6]. These methods are more accurate than indirect one provided that target $S o C$ is well determined, i.e. easy to achieve and time invariant.

A direct way to measure self-discharge of batteries consists on a full discharge to know the current quantity of charge in the battery. The problem lies on the definition of full discharge. Several standards [7-10] defined full discharge as a CC or CP discharge to the lower voltage limit of the cell $\left(U_{\min }\right)$. When using $U_{\min }$ as the stop criteria of a discharge, the quantity 


\begin{tabular}{|ll|}
\hline & \multicolumn{1}{c|}{ NOMENCLATURE } \\
$D o D$ & Depth of Discharge \\
$S o C$ & State of Charge \\
$T$ & Temperature \\
$Q_{0}$ & Initial capacity \\
$Q$ & Current capacity \\
$Q_{a}$ & Available capacity \\
$Q_{d}$ & Used capacity \\
$Q_{s d}$ & Self-discharge (reversible capacity loss) \\
$Q_{f}$ & Capacity fade between two successive RPT \\
$Q_{F}$ & Total capacity fade (from $t=0)$ \\
$Q_{l}$ & Total capacity losses between two successive RPT \\
$I_{s d}$ & Self-discharge current $\left(d Q_{s d} / d t\right)$ \\
$I_{f}$ & Irreversible leakage current $\left(d Q_{F} / d t\right)$ \\
$I_{L}$ & Leakage current $\left(d Q_{l} / d t\right)$ \\
\hline
\end{tabular}
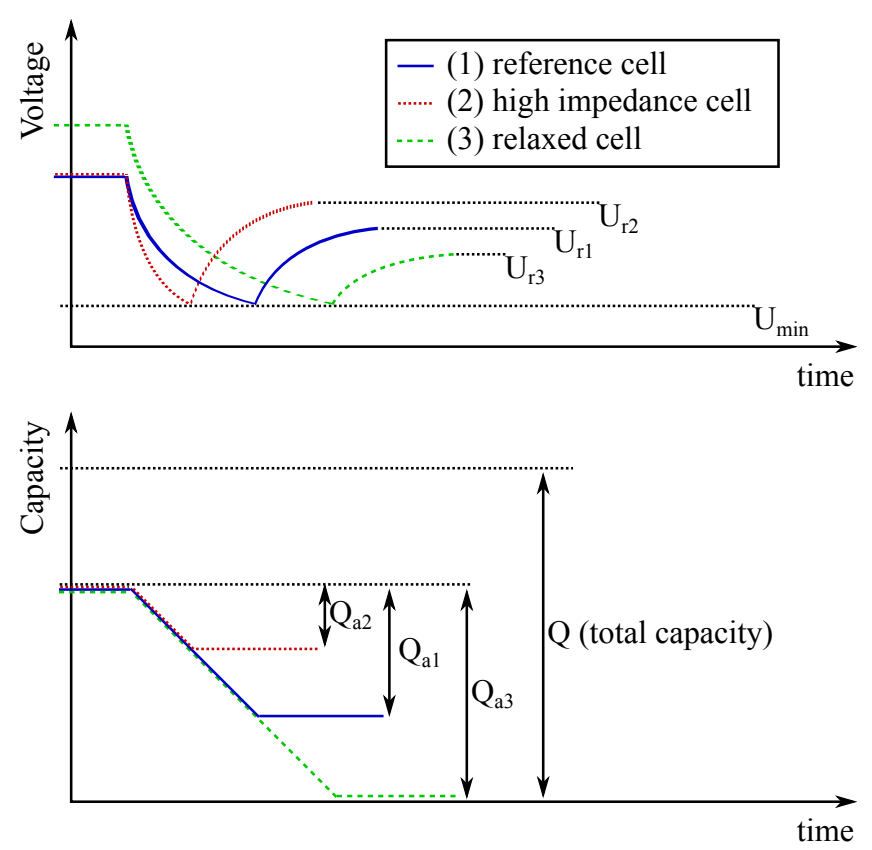

Figure 1: Influence of impedance and relaxation on available capacity measurement: (1) reference cell, (2) high impedance cell and (3) relaxed cell.

of charge taken off the battery will depend of impedance: if a battery is fresh a CC discharge will be deeper compared to an aged cell. This measure is also dependent of the relaxation state of the battery.

Figure 1 shows the influence of impedance and relaxation on available capacity measurement. In this example, three cells at the same initial $S o C$ are discharged according to a $\mathrm{CC}$ with $U_{\min }$ stop criteria. Cell (2) has a higher impedance than cell (1). Cell (3) is more relaxed than cell (1), for example cell (1) was used then discharged and cell (3) was used then disconnected one day and then discharged. The discharge is deeper for cell (3) than cell (1) and than cell (2): $Q_{a 3}>Q_{a 1}>$ $Q_{a 2}$. This effect is visible when looking at the voltage after a rest period: $U_{r 3}<U_{r 1}<U_{r 2}$. From this simple example it could be seen that the measure of the actual capacity of a battery depends on impedance of the cell and on duration of eventual relaxation phase.
Consequently, the self-discharge tests defined in [7-10] do not give an accurate measure of self-discharge. It is necessary to find a measurement protocol that is free of the influence of impedance or relaxation and suitable to separate self-discharge from capacity fade. The innovative method exposed in this work is a solution to such problem.

\section{DESCRIPTION OF USUAL PROTOCOLS FOR CAPACITY MEASUREMENT}

In fact, self-discharge tests cannot be performed separately from calendar ageing tests, because ageing and self-discharge phenomena act in the same timespan.

\section{A. Accelerated ageing tests}

In calendar ageing tests, mainly two factors $-T$ (temperature) and $S o C$ (State-of-Charge)- affect the degradation of battery performances (capacity fade and impedance increase). Usually these tests consist in a test matrix $(m \times n)$ of $m$ values of $T$ and $n$ values of SoC. Every cell is stored in open circuit conditions at a couple of values $(\mathrm{T}, \mathrm{SoC})$ during a relatively long period, usually several weeks to months.

Periodically, a RPT (Reference Performance Test) is performed to know the current value of capacity and impedance. RPT is normally carried out at the same temperature independently of ageing conditions, e.g.: $25{ }^{\circ} \mathrm{C}$, to be able to compare the performance evolution between every cell in the test matrix.

Basically the RPT is composed of four steps:

(i) Available capacity measurement $Q_{a}$.

(ii) Capacity measurement $Q$.

(iii) Impedance measurements at several $S o C$ levels.

(iv) Reset $\mathrm{SoC}$ for ageing.

Step (iii) is not in the scope of this paper and will not be considered thereafter.

Capacity $(Q)$ will decay over time because of irreversible capacity loss. However available capacity $\left(Q_{a}\right)$ evolution is influenced by both: irreversible and reversible capacity losses.

\section{B. Definitions and base equations}

For better understanding, in this section some useful definitions are included:

- Capacity $(Q)$ is the quantity of electric charge that can be stored (and then delivered) in a battery cell. This characteristic is affected by irreversible loss.

- Coulombic Effiency $(C E)$ is the relation between $Q_{c h a}$ and $Q_{\text {dis. }}$. Due to parasitic reactions, discharged capacity $\left(Q_{d i s}\right)$ is lower than charged capacity $\left(Q_{c h a}\right)$. For lithiumion batteries $C E>0.99$ after several initial cycles [2]. In this paper, we will consider $C E \simeq 1$ thus $Q=Q_{d i s}=Q_{c h a}$.

- Available capacity $\left(Q_{a}\right)$ is the quantity of electric charge that is currently stored in a battery cell. This characteristic is affected by reversible and irreversible losses.

- Discharged capacity $\left(Q_{d}\right)$ is the quantity of electric charge that has been delivered by a battery cell since the last full charge. 


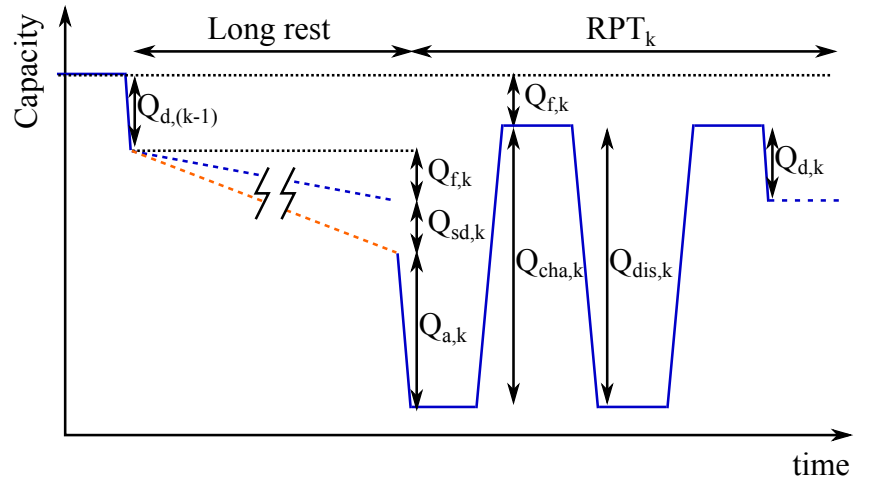

Figure 2: Capacity losses after long rest periods during the $k^{\text {th }}$ RPT.

- Self-discharged capacity $\left(Q_{s d}\right)$ is the reversible loss of electric charge.

- Capacity fade is the irreversible part of the capacity loss. In this paper, we will use $Q_{f}$ for the losses occurring between two successive RPTs and $Q_{F}$ for the cumulative capacity loss from initial capacity $\left(Q_{0}\right)$.

Equations 1 to 3 show the relations between these quantities. In these equations the index $k$ refers to the values of the variables measured during the $k^{t h}$ RPT as illustrated in figure 2 .

$$
\begin{gathered}
Q(k)=Q_{a}(k)+Q_{d}(k-1)+Q_{s d}(k) \\
Q_{f}(k)=Q(k-1)-Q(k) \\
Q_{F}(k)=Q_{0}-Q(k)
\end{gathered}
$$

\section{Charging protocol}

Full charge of lithium-ion cells is performed by a CCCV charge consisting in two phases (figure 3 ):

(i) $\mathrm{CC}$ phase: Charge at a given current rate to the maximum voltage $U_{\max }$.

(ii) $\mathrm{CV}$ phase: Keep the cell on floating condition at $U_{\max }$ until the current drops to $I_{\text {end }}$ (typically $\mathrm{C} / 20$ ). This phase ensures that the cell is completely charged regardless of impedance value of the cell.

\section{Capacity measurement protocols}

Generally the cell capacity $(Q)$ is measured with a full discharge. Previously, the cell must be fully charged by using the charging protocol given above. Capacity can be measured by a $\mathrm{CC}$ or a $\mathrm{CCCV}$ discharge.

1) Constant Current (CC): The most common way is by a CC discharge with stop condition of $U_{\min }$. The quantity of electric charge delivered by the battery in this manner $\left(Q_{C C}\right)$ depends of the voltage drop due to the internal impedance of the battery. For example, $Q_{C C}$ is higher in fresh cells or when discharged at low current rates or at high temperatures. Inversely, $Q_{C C}$ is lower in aged cells or when discharged at high current rates or at low temperatures. Peukert law and
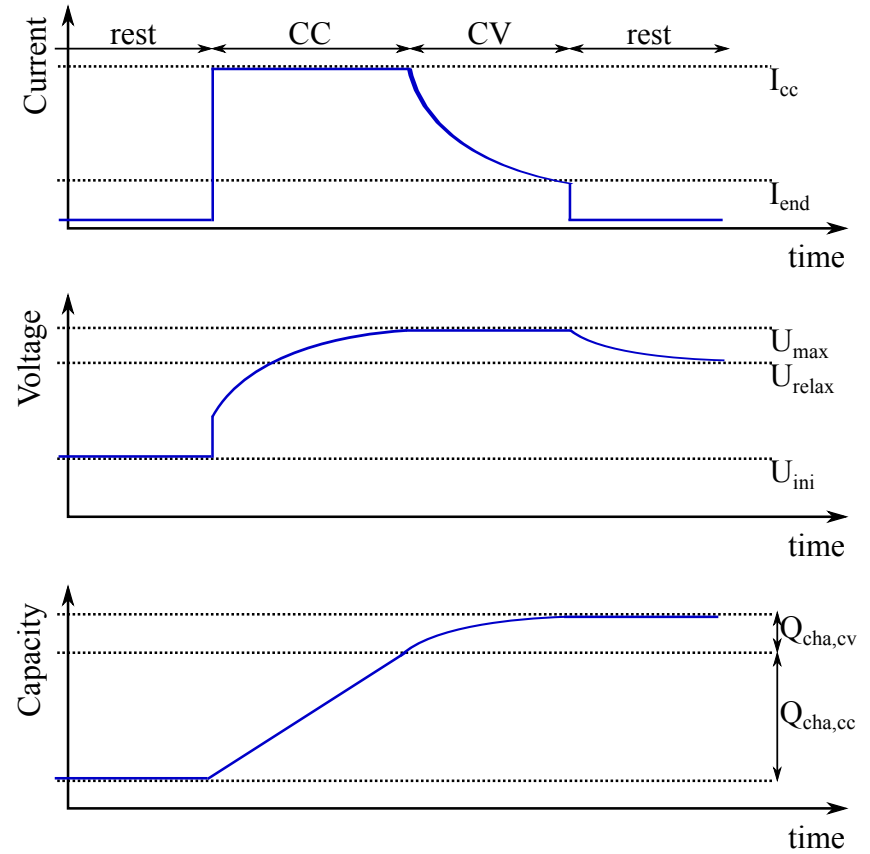

Figure 3: Charging protocol of a Lithium-ion battery.

other empiric laws [11] express capacity as a function of $T$ and discharge rate (C). Other authors discussed about the influence of this dependence on $S o C$ definition [12].

2) Constant Current - Constant Voltage (CCCV): In the same way as for the charging protocol, a CCCV discharge consist in two phases:

(i) $\mathrm{CC}$ phase: Discharge at a given current rate to the minimum voltage $U_{\min }$

(ii) $\mathrm{CV}$ phase: Keep the cell on floating condition at $U_{\min }$ until the current drops to $I_{\text {end }}$ (typically $\mathrm{C} / 20$ ).

The quantity of charge in this way $\left(Q_{C C C V}\right)$ is less impedance-dependent than preceding one $\left(Q_{C C}\right)$.

\section{INFLUENCE OF RELAXATION ON AVAILABLE CAPACITY MEASUREMENT}

Avalaible capacity measurement is the first step of a RPT. This measure can be performed by $\mathrm{CC}$ or CCCV discharge as indicated in the previous section. The direct way of measuring available capacity consists on simply integrate the current value over time during this initial discharge. An uncertainty of measure appears when $\mathrm{CC}$ discharge method is chosen because this measure depends on relaxation time and impedance.

To illustrate the relaxation effect, take for example one battery cell on which we perform three RPTs: $R P T_{0}, R P T_{1 h}$ et $R P T_{1 d}$ (table I). The three RPTs have the same final $Q_{d}$. Between $R P T_{0}$ et $R P T_{1 h}$ the cell must be disconnected (rest) during 1 hour. Between $R P T_{1 h}$ et $R P T_{1 d}$ the cell must be disconnected (rest) during 1 day.

Figure 4 shows the voltage and capacity evolutions for $R P T_{1 h}$ and $R P T_{1 d}$ during the firsts steps of the RPT:

(i) Available capacity measurement $Q_{a}$.

(ii) Rest.

(iii) Full CCCV charge $\left(Q_{c h a}\right)$. 
Table I: Chronogram.

\begin{tabular}{|l|l|l|l|l|}
\hline $\mathrm{RPT}_{0}$ & 1 hour rest & $\mathrm{RPT}_{1 h}$ & 1 day rest & $\mathrm{RPT}_{1 d}$ \\
\hline
\end{tabular}
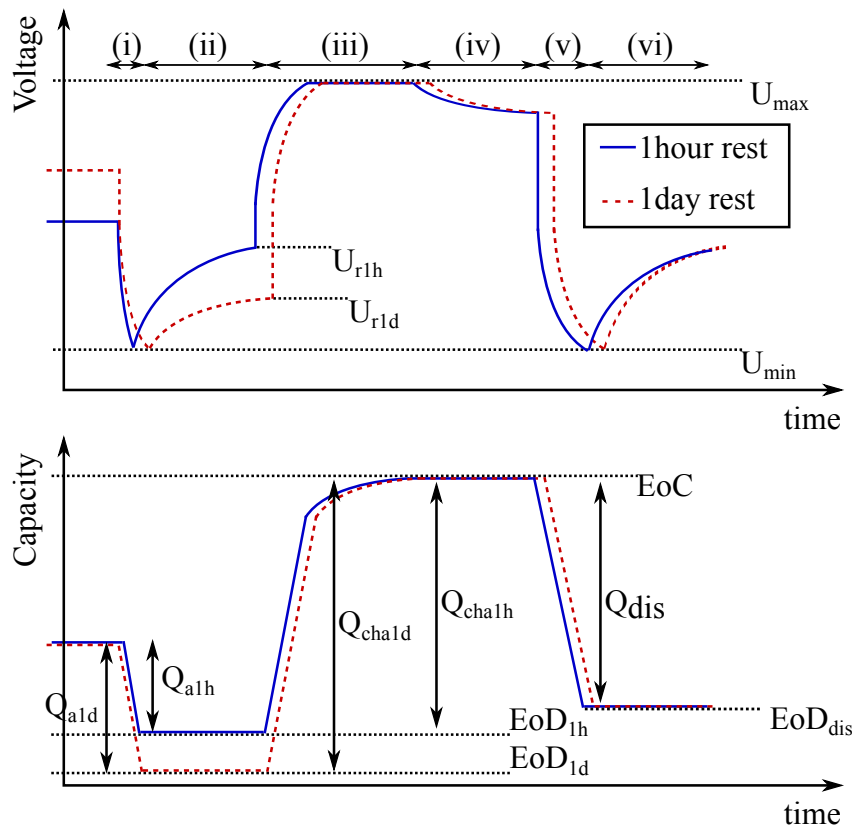

Figure 4: Relaxation effect on $Q_{a}$ measurement.

(iv) Rest.

(v) Full CC discharge $\left(Q_{d i s}\right)$.

(vi) Rest.

Because of the short period of time between these three RPTs, we can assume that no capacity losses occurred $\left(Q_{s d}=\right.$ $\left.Q_{f}=0\right)$. According to this hypothesis and from equations 1 to 3 , available capacity $\left(Q_{a}\right)$ and total capacity $(Q)$ must remain the same in each RPT independently of the rest time (1 hour and 1 day).

However, cell is more relaxed in $R P T_{1 d}$ because of the difference in the rest time. Then, the initial voltage is higher (figure 4) and the stop criteria $U_{\min }$ arrives later than in $R P T_{1 h}$. Hence, relaxation effect makes a greater $Q_{a}$ in $R P T_{1 d}$ than in $R P T_{1 h}$ (step (i)). This is in contradiction with the preceding equations $(1-3)$ and highlights the relaxation distortion in the $\mathrm{CC}$ discharge method. This distortion is quantifiable in figure 4 by taking a look on $E o D$ (End-ofDischarge) states: $E o D_{1 d}<E o D_{1 h}$, i.e. discharge is deeper when relaxation is higher.

A full CCCV charge is performed after the initial discharge (step (iii)). The CCCV mode ensures that $E o C$ (End-ofCharge) is independent of relaxation time. As the initial discharge was deeper in $R P T_{1 d}$ than in $R P T_{1 h}$, the charged capacity is greater in $R P T_{1 d}$ than $R P T_{1 h}$ :

$$
\left.\begin{array}{r}
E o D_{1 d}<E o D_{1 h} \\
E o C_{1 d}=E o C_{1 h}=E o C
\end{array}\right\} \Rightarrow Q_{c h a, 1 d}>Q_{c h a, 1 h}
$$

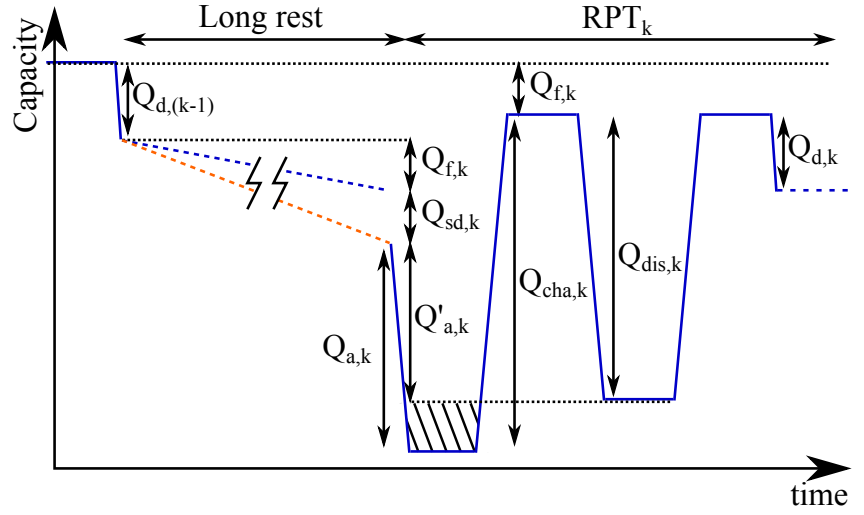

Figure 5: Indirect available capacity measure $\left(Q_{a}^{\prime}\right)$.

For the capacity measurement (full CC discharge, step (v)) the following relations are true:

$$
\left.\begin{array}{r}
E o C_{1 d}=E o C_{1 h} \\
E o D_{d i s, 1 d}=E o D_{d i s, 1 h}=E o D_{d i s}
\end{array}\right\} \Rightarrow Q_{d i s, 1 d}=Q_{d i s, 1 h}
$$

The final part of the RPT is the $S o C$ reset (full CCCV charge and partial CC discharge, $Q_{d}$ ) as in figure 2.

With a CC discharge method, it appears that the measurement of available capacity $Q_{a}$ is dependent on the duration of relaxation phase. This makes difficult to use $Q_{a}$ in any attempt to separate reversible and irreversible losses. On the contrary, the discharged capacity $Q_{\text {dis }}$ is independent of any relaxation phase. Therefore, in this way, irreversible losses $\left(Q_{f}\right)$ are measurable but reversible losses $\left(Q_{s d}\right)$ are not.

\section{NeW METHOd TO SEPARATE REVERSible AND IRREVERSIBLE LOSSES WITH NO INFLUENCE OF RELAXATION}

This new method lies on an indirect way of measuring the real available capacity $Q_{a}^{\prime}$. This quantity represents the measured available capacity if no relaxation effect had taken place. From figure 5 and with $C E=1$ :

$$
Q_{c h a}(k)-Q_{d i s}(k)=Q_{a}(k)-Q_{a}^{\prime}(k)
$$

Then:

$$
Q_{a}^{\prime}(k)=Q_{a}(k)+Q_{d i s}(k)-Q_{c h a}(k)
$$

From 5 we also obtain the following identity:

$$
Q_{d}(k)+Q_{f}(k)+Q_{s d}(k)+Q_{a}^{\prime}(k)=Q_{f}(k)+Q_{d i s}(k)
$$

Then:

$$
Q_{s d}(k)=Q_{d i s}(k)-Q_{a}^{\prime}(k)-Q_{d}(k)
$$

$Q_{a}^{\prime}$ is an indirect measure of the available capacity which is independent of relaxation state of the cell and capacity losses $\left(Q_{f}, Q_{s d}\right) . Q_{a}^{\prime}$ can be calculated with the equation 7 where $Q_{a}(k), Q_{c h a}(k)$ and $Q_{d i s}(k)$ are directly measurable by current integration over time. In this way we can decouple the measure of available capacity from relaxation phenomena and separate reversible from irreversible capacity losses by using equations 9 and 2 respectively. 
Table II: Cell and target $S o C\left(S o C_{t}\right)$ distribution on validation tests.

\begin{tabular}{|c|c|c|c|c|c|}
\hline Test no. & Cell no. & $S_{o} C_{t}(\%)$ & $t_{r 1}$ & $t_{r 2}$ & $t_{r 3}$ \\
\hline 1 & 1 & 10 & $5 \mathrm{~m}$ & $1 \mathrm{~h}$ & $1 \mathrm{~d}$ \\
\hline 2 & 2 & 50 & $5 \mathrm{~m}$ & $1 \mathrm{~h}$ & $1 \mathrm{~d}$ \\
\hline 3 & 3 & 90 & $5 \mathrm{~m}$ & $1 \mathrm{~h}$ & $1 \mathrm{~d}$ \\
\hline 4 & 1 & 50 & $5 \mathrm{~m}$ & $1 \mathrm{~h}$ & $1 \mathrm{~d}$ \\
\hline 5 & 2 & 90 & $5 \mathrm{~m}$ & $1 \mathrm{~h}$ & $1 \mathrm{~d}$ \\
\hline 6 & 3 & 10 & $5 \mathrm{~m}$ & $1 \mathrm{~h}$ & $1 \mathrm{~d}$ \\
\hline
\end{tabular}

Table III: Results of validation tests. $Q_{a}$ and $Q_{a}^{\prime}$ are expressed in $\%$ of the nominal capacity.

\begin{tabular}{|c|c|c|c|c|c|c|}
\hline Test no. & 1 & 6 & 2 & 4 & 3 & 5 \\
\hline Cell no. & 1 & 3 & 2 & 1 & 3 & 2 \\
\hline$S o C_{t}(\%)$ & 10 & 10 & 50 & 50 & 90 & 90 \\
\hline \hline$Q_{a}\left(t_{r}=5 \mathrm{~m}\right)$ & 9.51 & 10.06 & 49.19 & 49.35 & 90.12 & 89.09 \\
\hline$Q_{a}\left(t_{r}=1 \mathrm{~h}\right)$ & 9.71 & 10.25 & 49.25 & 49.37 & 90.07 & 89.01 \\
\hline$Q_{a}\left(t_{r}=1 \mathrm{~d}\right)$ & 9.76 & 10.28 & 49.13 & 49.26 & 89.42 & 88.37 \\
\hline$\Delta Q_{a}$ & 0.25 & 0.22 & 0.12 & 0.11 & 0.70 & 0.72 \\
\hline \hline$Q_{a}^{\prime}\left(t_{r}=5 \mathrm{~m}\right)$ & 9.25 & 9.84 & 48.68 & 49.21 & 89.92 & 88.54 \\
\hline$Q_{a}^{\prime}\left(t_{r}=1 \mathrm{~h}\right)$ & 9.30 & 9.83 & 48.74 & 49.21 & 89.94 & 88.53 \\
\hline$Q_{a}^{\prime}\left(t_{r}=1 \mathrm{~d}\right)$ & 9.30 & 9.88 & 48.71 & 49.16 & 89.82 & 88.37 \\
\hline$\Delta Q_{a}^{\prime}$ & 0.05 & 0.04 & 0.06 & 0.05 & 0.11 & 0.17 \\
\hline \hline$P_{g}$ & 4.9 & 4.9 & 2.0 & 2.1 & 6.3 & 4.3 \\
\hline
\end{tabular}

\section{A. Experimental validation}

In order to validate the new method to calculate the available capacity, some tests were carried out on three fresh cells KOKAM SLPB $283452 \mathrm{H}$. The nominal capacity of this cells is $350 \mathrm{mAh}$ and their chemical composition is NMC / graphite.

The tests consisted on:

(i) Full CCCV charge

(ii) Partial CC discharge to a target $\mathrm{SoC}\left(\mathrm{SoC}_{t}\right)$

(iii) Rest for $t_{r}$

(iv) Full CC discharge $\left(Q_{a}\right)$

Three values of $t_{r}$ ( 5 minutes, 1 hour and 1 day) and three values of target $S o C(10,50$ and $90 \%)$ have been tested. Discharged capacity measured in step (iv) would be different for each $t_{r}$ according to the relaxation state. The full sequence of tests applied on three different cells is shown in table II. Capacity measurements at the beginning and at the end of the tests allow to check if any irreversible capacity losses occurred during the test.

Table III summarizes the results of the validation tests. For every test, $Q_{a}$ as well as $Q_{a}^{\prime}$ are reported in this table. $Q_{a}$ is computed by integrating the current value over time during step (iv). $Q_{a}^{\prime}$ is computed following the equation 7 . The uncertainty of each measure $\Delta Q_{a}$ and $\Delta Q_{a}^{\prime}$ are computed as the difference between the maximum and the minimum value obtained in one single test $\left(t_{r}=5 \mathrm{~m}, 1 \mathrm{~h}, 1 \mathrm{~d}\right)$. Finally, the precision gain $\left(P_{g}\right)$ is the relation between $\Delta Q_{a}$ and $\Delta Q_{a}^{\prime}$ :

$$
P_{g}=\Delta Q_{a} / \Delta Q_{a}^{\prime}
$$

Precision gain is around 2.1 for $S o C 50 \%, 4.9$ in $S o C$ $10 \%$ and 4.3 to 6.3 in $S o C 90 \%$ (table III). This validate the new method as a more precise way to measure the available capacity.

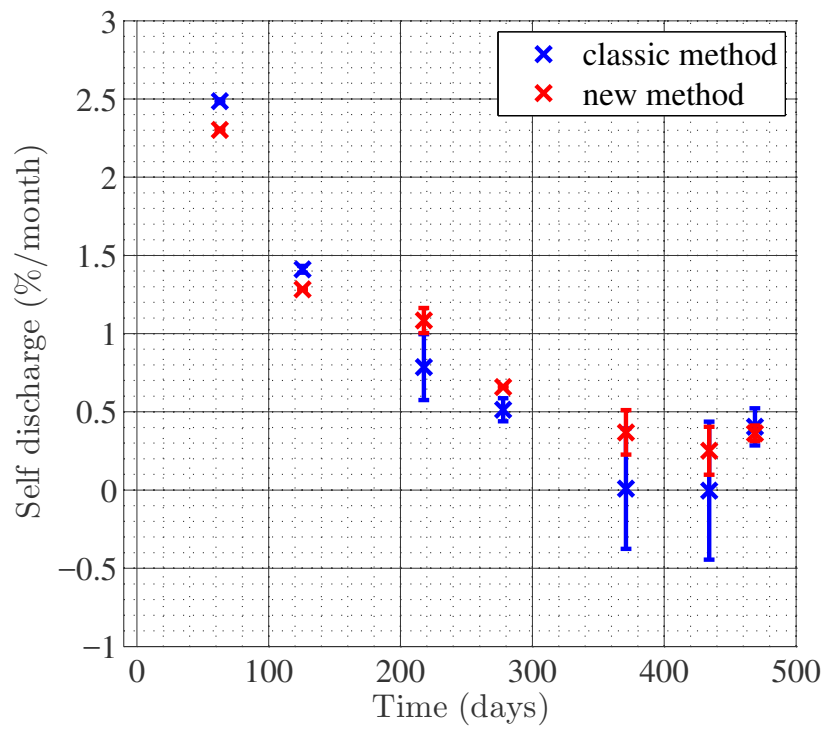

Figure 6: Measure of self-discharge in T60SoC65 KOKAM cells using the direct way (blue) and the new method (red). The crosses represent the mean value between two cells and the error bars represent the max and min values.

\section{B. Case study: Calendar ageing tests}

As an illustration of our method, we applied it to the measured results of one SIMCAL test (ageing at $60^{\circ} \mathrm{C}$ and $S o C$ $65 \%$ ) for which the loss of capacity was $20 \%$ after 500 days of test. Figure 6 shows the result of self-discharge calculated by the classic method $\left(Q_{a}\right)$, and by the new method $\left(Q_{a}^{\prime}\right)$. When using $Q_{a}$, relaxation and impedance increase distort self-discharge calculation giving more spread out results. In particular, "negative" self-discharge (meaning "self-charge") could appear when using the classic method which has no physical signification.

\section{MOdELling CAPACITY LOSSES}

In the previous section, we have shown that the new method improves the self-discharge measurement accuracy and permits to better study self-discharge as a function of $\mathrm{T}$ and SoC. It is illustrated by the result for one SIMCAL test (figure 6). In this section, we propose to generalize the result to the complete SIMCAL tests and to model both irreversible and reversible capacity losses to better understand how capacity varies over time within lithium-ion batteries.

The cell technology considered in this paper is KOKAM SLPB 70205130P. The nominal capacity for this type of cell is $12 \mathrm{Ah}$ and the chemical composition is NMC / graphite.

Experimental data belong to the experimental campaign carried out during SIMCAL project [13]. In this project, 6 different technologies of lithium-ion battery cells have been tested in calendar ageing at three temperatures $(30,45$ and $60^{\circ} \mathrm{C}$ ) and three $\operatorname{SoC}(30,65$ and $100 \%)$. Each couple of values $(T, S o C)$ was assigned to three different cells to improve the representativeness of the results. 
We will firstly study irreversible capacity losses with a classical approach (part A : Capacity fade model). That means to define and parameter a capacity fade model as a function of $t, T$ and $S o C$. Afterwards (part B : Global capacity losses model), we will focus in an approach where reversible and irreversible losses are studied together. On this purpose, we use the accurate estimation of the self-discharge developed previously in this paper.

Actually the goal is to find a model allowing to evaluate the total capacity loss throughout the cell's lifespan while distinguishing reversible (self-discharge) and irreversible (capacity fade) losses.

\section{A. Capacity fade model}

Many preceding works focused on irreversible loss modelling, for example [14-20]. In lithium-ion cells calendar ageing the main mechanism is the loss of lithium inventory by SEI layer formation and growing [1], [2].

Some works are based on the modelling of chemical side reactions leading to capacity fade: specially the evolution of the electrolyte reduction to form SEI layer [14-16]. Other works use a more empiric approach [17-20].

For the purpose of this paper, a pure empiric approach is very appropriated. The evolution of capacity during calendar ageing in this type of cells are mainly linear over time, as shown in figure 7. A linear approximation can be performed to model capacity fade (equation 11), where $I_{f}$ depends on $T$ and $D o D$ according to an Eyring law (equation 12), with $D o D=$ $100-S o C$ and $k$ the Boltzmann constant $\left(8.617 \cdot 10^{-5} \mathrm{eV} / \mathrm{K}\right)$. The model parameters $A, E_{a}$ (activation energy), $B$ and $C$ are constant.

$$
\begin{gathered}
Q_{F}(T, D o D, t)=I_{f}(T, D o D) \cdot t \\
I_{f}(T, D o D)=A \cdot e^{\left(\frac{-E_{a}}{k \cdot T}+B \cdot D o D+C \cdot \frac{D o D}{T}\right)}
\end{gathered}
$$

The figure 7 reveals that some cells seem to regenerate their capacity (i.e. negative capacity fade) at the beginning of the tests if ageing stress factors are low $\left(T=45\right.$ or $30^{\circ} \mathrm{C}$, $S o C=65$ or $30 \%$ ). Specially T30SoC 30 cells where measured capacity fade was negative during the entire test duration.

This phenomenon is probably due to an initial decrease of impedance in the firsts stages of SEI formation. As stress factors accelerate the ageing mechanisms, the mechanisms leading to an initial increase of capacity act much more slowly for T30SoC30 than for other cells. In fact capacity measurements are strongly dependent of impedance when they are performed at medium/high rates. By performing capacity measurements at low rates, for example $\mathrm{C} / 5$ or lower, distortion due to this initial decrease of impedance is minimised [21], [22].

Negative values cause a problem from a numerical point of view becoming an obstacle for the solution of equation 12 : exponential function $\left(e^{x}\right)$ returns only positive values for every value of $x$, given that $x$ is a real number.

Experimental capacity measurement in SIMCAL project were performed only at $1 \mathrm{C}$ rate and there is no easy way

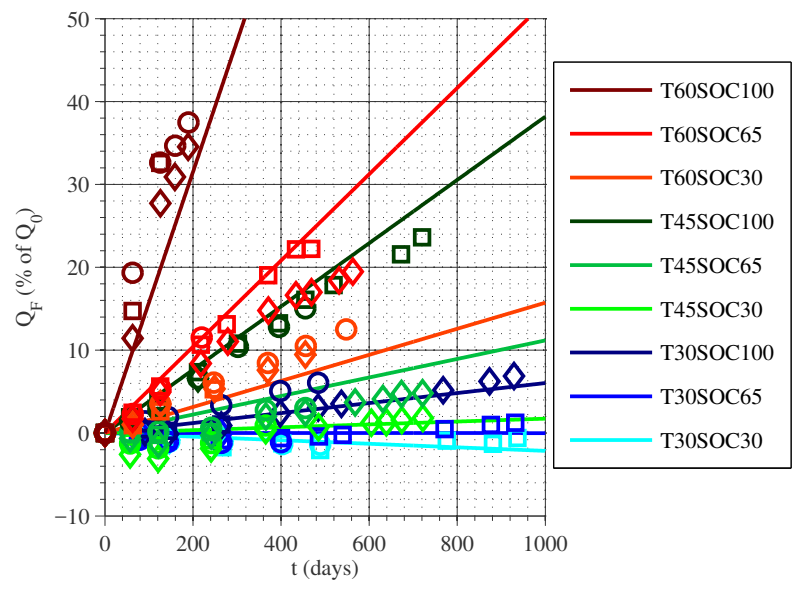

Figure 7: Capacity fade. Lines: model simulation, points: experimental data. Circles, squares and diamonds represent experimental data respectively to cell number 1,2 and 3 in each couple of values (T, SoC).

to estimate the low rate values of capacity with no additional experiments. So, in the lack of additional experimental data, we correct the capacity fade values by adding a constant value $I_{f 0}$ (equation 13). $I_{f}^{\prime}(T, D o D)$ in equation 14 follows an Eyring law.

$$
\begin{gathered}
I_{f}^{\prime}=I_{f}+I_{f 0} \\
I_{f}^{\prime}(T, D o D)=A^{\prime} \cdot e^{\left(\frac{-E_{a}^{\prime}}{k \cdot T}+B^{\prime} \cdot D o D+C^{\prime} \cdot \frac{D o D}{T}\right)}
\end{gathered}
$$

The parameter identification for the capacity fade model is performed by the means of a logarithm transformation of equation 14:

$$
\ln \left(I_{f}^{\prime}\right)=\ln \left(A^{\prime}\right)-\frac{E_{a}^{\prime}}{k \cdot T}+B^{\prime} \cdot D o D+C^{\prime} \cdot \frac{D o D}{T}
$$

Equation 15 is equivalent to the equation of a surface: $z=a+b x+c y+d x y$, with: $z=\ln \left(I_{f}^{\prime}\right), x=1 / T$, $y=D o D, a=\ln \left(A^{\prime}\right), b=-E_{a}^{\prime} / k, c=B^{\prime}$ and $d=C^{\prime}$. The parameter identification is achieved by least squares fitting of experimental values on this expression.

We have fixed $I_{f 0}$ to $0.1 \% /$ month and performed the parameter identification of $A, E_{a}, B$ and $C$ in equation 14 (table IV). Figure 7 shows the simulation results (lines) beside the experimental values (points). The maximum simulation error (table V) are lower than 5\% for all ageing conditions, except for T60 SoC65 and SoC100 cells with 9.8\% and 12.8\% respectively.

When the stress factor levels are too high (T60 SoC65 and SoC100) the cell degradation can lead to disperse results. The first reason is that small differences in the stress values are more important when the stress values are high: as Arrhenius and Eyring laws indicate, the influence of stress factor levels on battery degradation are exponential. Another reason is that small manufacturing differences make each cell different. The 
sensitiveness of each cell to ageing stress may be also different, mainly at higher values of stress factors. For example, in figure 7 the dispersion in the experimental values of the capacity fade for T60SoC65 cells is about 5\% at $t=450$ days.

The accuracy of this model could be improved by taking into account the $S o C$ drift caused by the capacity fade, as in preceding works [23]. But for the purpose of the present work the model is accurate enough and simple as it is.

\section{B. Global capacity losses model}

Figure 6 suggests that there is a relationship between self-discharge and capacity fade. This section is intended to model all capacity losses occurring inside the battery cells. In other words we will attempt to develop a global model for both type of capacity loss (self discharge and capacity fade) simultaneously.

Equation 16 expresses the available capacity as a time function between two successive RPT for a cell in ageing testing. $Q_{a 0, k-1}$ is the available capacity at the end of $\mathrm{RPT}_{k-1}$ and $I$ is the current through the battery cell.

$$
Q_{a}(t)=\int_{k-1}^{t} I \cdot d t+Q_{a 0, k-1}-Q_{s d}(t)-Q_{f}(t)
$$

The aggregation of self-discharge $\left(Q_{s d}\right)$ and capacity fade $\left(Q_{f}\right)$ to form the total capacity loss $\left(Q_{l}\right)$ leads to equation 17:

$$
Q_{a}(t)=\int_{k-1}^{t} I \cdot d t+Q_{a 0, k-1}-Q_{l}(t)
$$

During the ageing process the exact values of capacity losses as a function of time $\left(Q_{s d}(t)\right.$ and $\left.Q_{f}(t)\right)$ remain unknown. Only during each RPT these losses can be evaluated $\left(Q_{s d, k}=\right.$ $Q_{s d}\left(t=t_{R P T_{k}}\right)$ and $\left.Q_{f, k}=Q_{f}\left(t=t_{R P T_{k}}\right)\right)$.

Equation 18 is the derivative of the equation 17. In this equation, the derivative of the available capacity $\left(d Q_{a} / d t\right)$ is

Table IV: $Q_{F}$ model parameters.

\begin{tabular}{|c|c|c|}
\hline Parameter & Units & Value \\
\hline \hline$A^{\prime}$ & $\% /$ month & $1.45 \cdot 10^{+13}$ \\
\hline$E_{a}^{\prime}$ & $\mathrm{eV}$ & 0.825 \\
\hline$B^{\prime}$ & (no units) & $-3.98 \cdot 10^{-2}$ \\
\hline$C^{\prime}$ & $\mathrm{eV}$ & 3.09 \\
\hline
\end{tabular}

Table V: Maximum $Q_{F}$ simulation error for each storage condition.

\begin{tabular}{|c|c|c|}
\hline SOC $(\%)$ & $\mathrm{T}\left({ }^{\circ} \mathrm{C}\right)$ & Error $\left(\%\right.$ of $\left.Q_{0}\right)$ \\
\hline \hline 30 & 30 & 1.4 \\
\hline 30 & 45 & 3.3 \\
\hline 30 & 60 & 3.9 \\
\hline 65 & 30 & 1.3 \\
\hline 65 & 45 & 3.3 \\
\hline 65 & 60 & 9.8 \\
\hline 100 & 30 & 3.1 \\
\hline 100 & 45 & 4.1 \\
\hline 100 & 60 & 12.8 \\
\hline
\end{tabular}

expressed as the sum of the current through the cell $I(t)$ and the leakage current $I_{L}(t)$.

$$
\frac{d Q_{a}}{d t}=I(t)-I_{L}(t)
$$

During calendar ageing tests the current $(I(t))$ is zero in the period between two RPTs. In this conditions $d Q_{a} / d t$ depends entirely of the leakage current, as in equation 19:

$$
I_{L}(t)=-\frac{d Q_{a}}{d t}
$$

According to a semi-empirical approach, leakage current is linked to side reactions' rates. As it can be inferred from the theory stated by [3], an exponential decay model appears to be consistent to express the time evolution of the leakage curent (equation 20). In this equation $I_{L 0}$ represents the initial leakage current, which decreases at a rate fixed by $\lambda$. On the basis of the hypothesis that side reactions are partially reversible, $\lambda$ has two components: $\lambda_{s d}$ and $\lambda_{f}$, corresponding to self-discharge and capacity fade respectively.

$$
I_{L}(t)=I_{L 0} \cdot e^{\lambda \cdot t}=I_{L 0} \cdot e^{\left(\lambda_{s d}+\lambda_{f}\right) \cdot t}
$$

In order to model the leakage current over the battery's lifespan, we can consider two different dynamics: short and long-term. Short-term dynamic consists of modelling the time evolution of $I_{L}$ in the interval between two successive RPTs. As explained before, this is not possible with the available data from SIMCAL. The problem lies in the absence of necessary experimental data for identifying such evolution, because self-discharge process is interrupted by the RPT. This makes impossible any identification of the parameters $I_{L 0}, \lambda_{s d}$ and $\lambda_{f}$ in equation 20 .

Long-term dynamic consists on evaluating the evolution of $I_{L}(t)$ throughout cell ageing. The model that we propose in this paper (equation 21) is based on the exponential decay expresion in equation 20 .

$$
I_{L}\left(t, T, D o D, I_{f}\right)=I_{\infty}(T, D o D) \cdot\left(1+e^{1-\lambda\left(I_{f}\right) \cdot t}\right)
$$

By regarding experimental data, leakage current follows an exponential decay converging to $I_{\infty}$. This limit value $\left(I_{\infty}\right)$ depends mainly of storage conditions $(T, D o D)$. As battery cell degrades, leakage current converges more or less rapidly to $I_{\infty}$. Therefore, convergence speed depends of cell ageing $\left(Q_{F}\right)$, and more precisely of irreversible leakage current $\left(I_{f}\right)$ : $\lambda\left(I_{f}\right)$.

The model parameter identification $\left(I_{\infty}\right.$ and $\left.\lambda\right)$ as a function of factors $T, D_{o} D$ and $I_{f}$ can be performed in two steps:

- identification of $I_{\infty}$ as a function of $T$ and $D o D$.

- identification de $\lambda$ as a function of $I_{f}$.

First parameter, $I_{\infty}$, can be modelled by using the generalized Eyring relationship, equation 22, as it has be done for irreversible losses $\left(I_{f}\right)$. Notice that, unlike $I_{f}$ model, this model does not contain any interaction term $(C$ parameter $)$ linking $T$ and $D o D$ : a model without interactions is accurate 
enough to evaluate the dependence of $I_{\infty}$ over $T$ and $D o D$. The obtained parameter values are collected in table VI.

$$
I_{\infty}(T, D o D)=A_{\infty} \cdot e^{\left(\frac{-E a \infty}{k \cdot T}+B_{\infty} \cdot D o D\right)}
$$

Once $I_{\infty}(T, D o D)$ is identified, the second step consist on estimating how leakage current converges to $I_{\infty}$ as a function of capacity fade. Equation 23 is an empiric expression that fits $\lambda$ as a function of $I_{f}^{\prime}$, with $I_{f}^{\prime}$ expressed by equation 14 .

$$
\lambda\left(I_{f}^{\prime}\right)=\frac{1}{76+\ln \left(I_{f}^{\prime}\right) \cdot 19.1}
$$

The simulation results are visible in figures 8 and 9 . Figure 10 shows the simulation errors over time for each couple $T, S o C$. The maximum error values are between 2 and $3 \%$ for SoC100 cells and lower than $1 \%$ for all other cells, as indicated in table VII. This results are satisfactory.

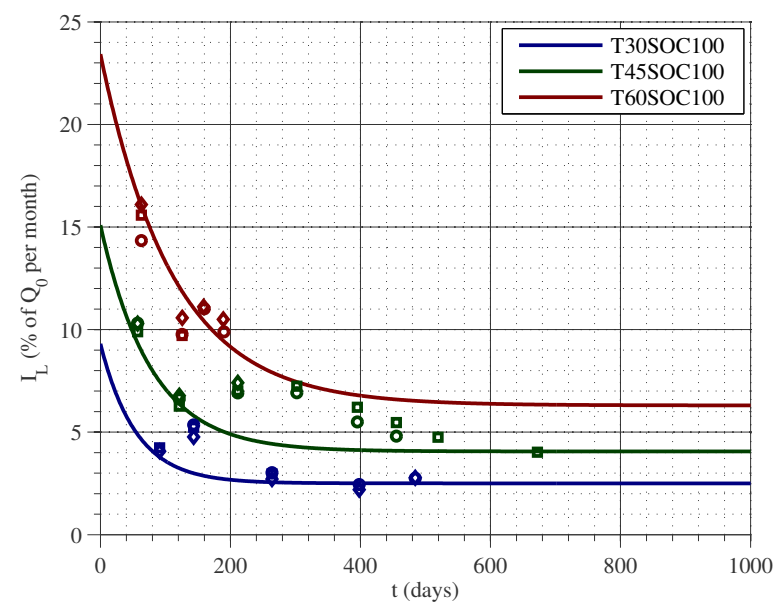

Figure 8: Leakage current in SoC100 cells. Lines: model simulation, points: experimental data.

Table VI: $I_{\infty}$ model parameters.

\begin{tabular}{|c|c|c|}
\hline Parameter & Units & Value \\
\hline \hline$A_{\infty}$ & $\% /$ month & $2.85 \cdot 10^{+5}$ \\
\hline$E_{a \infty}$ & $\mathrm{eV}$ & 0.306 \\
\hline$B_{\infty}$ & (no units) & $-3.11 \cdot 10^{-2}$ \\
\hline
\end{tabular}

Table VII: Maximum $I_{L}$ simulation error for each storage condition.

\begin{tabular}{|c|c|c|}
\hline SOC $(\%)$ & $\mathrm{T}\left({ }^{\circ} \mathrm{C}\right)$ & Error (\% of $Q_{0}$ per month) \\
\hline \hline 30 & 30 & 0.15 \\
\hline 30 & 45 & 0.48 \\
\hline 30 & 60 & 0.77 \\
\hline 65 & 30 & 0.33 \\
\hline 65 & 45 & 0.72 \\
\hline 65 & 60 & 0.88 \\
\hline 100 & 30 & 2.36 \\
\hline 100 & 45 & 2.96 \\
\hline 100 & 60 & 2.15 \\
\hline
\end{tabular}

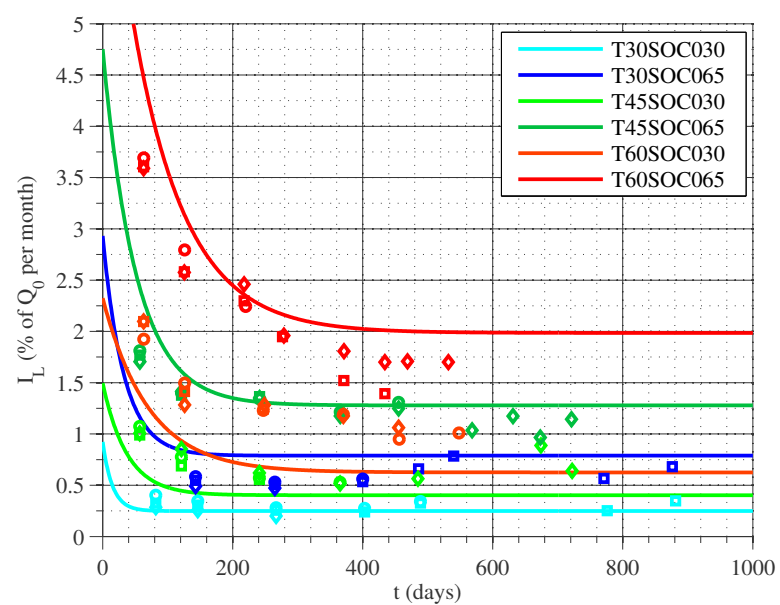

Figure 9: Leakage current in SoC65 and SoC30 cells. Lines: model simulation, points: experimental data.

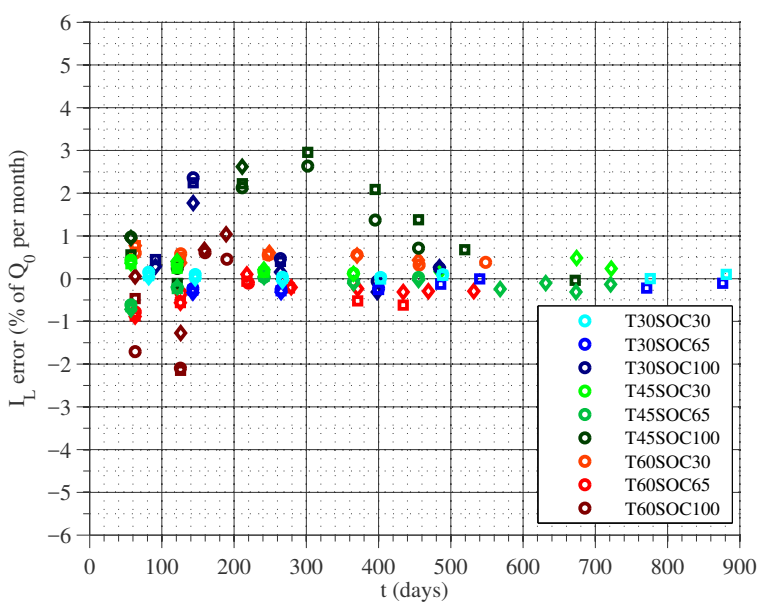

Figure 10: Simulation error of $I_{L}$ model versus time for all the storage conditions.

\section{DICUSSION}

We have proposed a capacity fade model $\left(I_{f}\right)$ and a global capacity loss model $\left(I_{L}\right)$. The first one is used to feed the global capacity loss model, because it seems that the reversible part of capacity losses (self-discharge) decreases as a function of irreversible losses (capacity fade).

We can afterwards obtain by a simple subtraction $\left(I_{s d}=\right.$ $\left.I_{L}-I_{f}\right)$ the reversible part of the leakage current. In this way, figures 11 and 12 show that self-discharge is dependent of storing conditions $T$ and $S o C$ as of capacity fade. Each cell stored at a couple of values $T, S o C$ has a self-discharge current converging more or less rapidly to a constant value $\left(I_{\infty}\right)$. The limit value depends mainly of storing conditions $\left(I_{\infty}=I_{\infty}(T, S o C)\right)$.

Further work could consist in using this model in order to estimate the state of health $(\mathrm{SoH})$ by simply measuring its self-discharge instead to perform a full discharge to know the current capacity. $\mathrm{SoH}$ can be expressed as a function of $Q_{F}$ : 


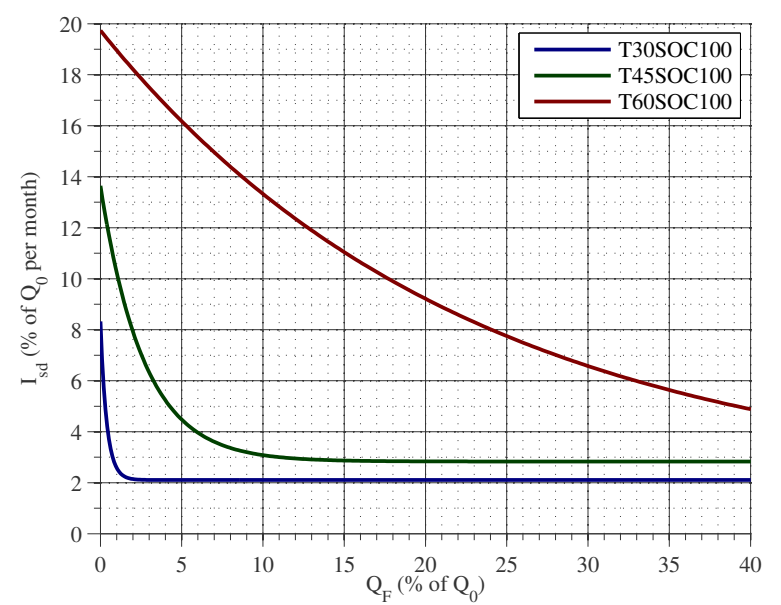

Figure 11: Self-discharge current versus capacity fade simulation in SoC100 cells.

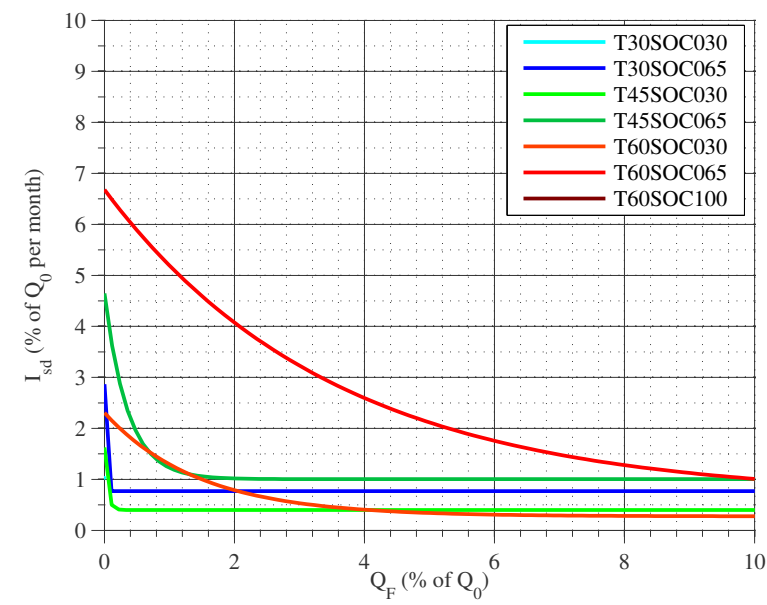

Figure 12: Self-discharge current versus capacity fade simulation in SoC65 and SoC30 cells.

$$
S o H=100 \cdot\left(1-\frac{Q_{F}}{Q_{0}}\right)
$$

For example, a protocol consisting on three steps can be considered:

(i) Fully charge the battery at ambient temperature.

(ii) Put the battery on rest condition at high temperature for a given period of time (e.g.: $60^{\circ} \mathrm{C}, 3$ days).

(iii) Fully charge the battery at ambient temperature to estimate self-discharge.

As shown in figures 11 and 12, self-discharge sensitivity is higher with higher temperatures. For example, at $60^{\circ} \mathrm{C}$, selfdischarge rate varies from about 20 to $5 \% /$ month while $Q_{F}$ is between 0 and $40 \%$. This is the reason why in step (ii) the battery should be put in rest conditions at high temperature.

If a cell is stored during three days at $60^{\circ} \mathrm{C}$ and $100 \% \mathrm{SoC}$, it will self-discharge about $2 \%$ when the cell is new $\left(Q_{F}=\right.$ $0 \%$ ) whereas self-discharge will be about $0.6 \%$ at end of life $\left(Q_{F}=30 \%\right)$.
The main inconvenient of this $\mathrm{SoH}$ measurement protocol is the degradation occurring during the rest period at high temperature. In this example, 3 days of rest at $60^{\circ} \mathrm{C}$ and $100 \% \mathrm{SoC}$ causes an irreversible capacity loss of about $0.5 \%$ (equations 11 and 12).

\section{CONCLUSION}

The common way for measuring available capacity consists on counting the electric charge during a full CC discharge with a stop condition of $U_{\min }$. The voltage limit strongly depends of the voltage drop caused by the cell's internal impedance and relaxation state. We propose in this work an indirect way to measure available capacity without changing the RPT protocol, by taking into account the full charge and full discharge following the first discharge.

The method has been validated by 6 tests on three different cells, three $S o C$ levels and three relaxation times. From these experimental results, the new method is 2 to 6 times more precise than the classic way, especially at high and low $S o C$ levels (90 and 10\%). This precision improvement allows a better assessment of self-discharge as illustrated by an application of the method on results of ageing tests from the SIMCAL project.

\section{ACKNOWLEDGMENT}

This work uses data from the SIMCAL project. SIMCAL was funded by the French National Research Agency (ANR) under the SIMCAL research program. SIMCAL network partners are CEA, EDF, EIGSI, IFPEN, IFSTTAR, IMS, LEC, LMS-Imagine, LRCS, PSA, RENAULT, SAFT and VALEO.

\section{REFERENCES}

[1] J. Vetter, P. Novák, M. Wagner, C. Veit, K.-C. Möller, J. Besenhard, M. Winter, M. Wohlfahrt-Mehrens, C. Vogler, and A. Hammouche, "Ageing mechanisms in lithium-ion batteries," Journal of Power Sources, vol. 147, no. 1 - 2, pp. $269-281,2005$.

[2] M. Kassem and C. Delacourt, "Postmortem analysis of calendar-aged graphite/LiFePO4 cells," Journal of Power Sources, vol. 235, pp. 159 - 171, 2013.

[3] R. Yazami and Y. F. Reynier, "Mechanism of self-discharge in graphite-lithium anode," Electrochimica Acta, vol. 47, no. 8, pp. 1217 $-1223,2002$.

[4] Y. Reynier, R. Yazami, and B. Fultz, "Thermodynamics and kinetics of self-discharge in graphite-lithium electrodes," in Seventeenth Annual Battery Conference on Applications and Advances. Proceedings of Conference (Cat. No.02TH8576), pp. 145-150.

[5] Y. Diab, P. Venet, H. Gualous, and G. Rojat, "Self-Discharge Characterization and Modeling of Electrochemical Capacitor Used for Power Electronics Applications," IEEE Transactions on Power Electronics, vol. 24, no. 2, pp. 510-517, Feb 2009.

[6] A. H. Zimmerman, "Self-discharge losses in lithium-ion cells," IEEE Aerospace and Electronic Systems Magazine, vol. 19, no. 2, pp. 19-24, Feb 2004.

[7] J. R. Belt, Battery Test Manual For Plug-In Hybrid Electric Vehicles, Idaho National Laboratory, Sep. 2010.

[8] J. P. Christophersen, Battery Test Manual For Electric Vehicles, Idaho National Laboratory, 2015.

[9] ISO 12405-1, Electrically propelled road vehicles - Test specification for lithium-ion traction battery packs and systems - Part 1: High-power applications, 2011.

[10] ISO 12405-2, Electrically propelled road vehicles - Test specification for lithium-ion traction battery packs and systems - Part 2: High-energy applications, 2012. 
[11] N. Omar, P. V. d. Bossche, T. Coosemans, and J. V. Mierlo, "Peukert Revisited - Critical Appraisal and Need for Modification for LithiumIon Batteries," Energies, vol. 6, no. 11, pp. 5625-5641, 2013.

[12] M. Dubarry, V. Svoboda, R. Hwu, and B. Y. Liaw, "Capacity and power fading mechanism identification from a commercial cell evaluation," Journal of Power Sources, vol. 165, no. 2, pp. 566 - 572, 2007.

[13] A. Delaille, S. Grolleau, F. Duclaud, J. Bernard, R. Revel, S. Pelissier, E. Redondo-Iglesias, J.-M. Vinassa, A. Eddahech, C. Forgez, M. Kassem, S. Joly, D. Porcellato, P. Gyan, S. Bourlot, and M. Ouattara-Brigaudet, "Simcal Project: Calendar Aging Results Obtained On a Panel of 6 Commercial Li-Ion Cells," in ECS Meeting Abstracts, no. 14, p. 1191.

[14] R. Spotnitz, "Simulation of capacity fade in lithium-ion batteries," Journal of Power Sources, vol. 113, no. 1, pp. 72 - 80, 2003.

[15] P. Ramadass, B. Haran, R. White, and B. N. Popov, "Mathematical modeling of the capacity fade of Li-ion cells," Journal of Power Sources, vol. 123, no. 2, pp. $230-240,2003$.

[16] E. Prada, D. Di Domenico, Y. Creff, J. Bernard, V. Sauvant-Moynot, and F. Huet, "A Simplified Electrochemical and Thermal Aging Model of LiFePO4-Graphite Li-ion Batteries: Power and Capacity Fade Simulations," Journal of The Electrochemical Society, vol. 160, no. 4, pp. A616-A628, 2013.

[17] J. Wang, P. Liu, J. Hicks-Garner, E. Sherman, S. Soukiazian, M. Verbrugge, H. Tataria, J. Musser, and P. Finamore, "Cycle-life model for graphite-LiFePO4 cells," Journal of Power Sources, vol. 196, no. 8, pp. 3942-3948, Apr. 2011

[18] M. Ecker, J. B. Gerschler, J. Vogel, S. Käbitz, F. Hust, P. Dechent, and D. U. Sauer, "Development of a lifetime prediction model for lithium-ion batteries based on extended accelerated aging test data," Journal of Power Sources, vol. 215, pp. 248 - 257, 2012.

[19] A. Eddahech, O. Briat, E. Woirgard, and J. Vinassa, "Remaining useful life prediction of lithium batteries in calendar ageing for automotive applications," Microelectronics Reliability, vol. 52, no. 9-10, pp. 2438 $-2442,2012$

[20] S. Grolleau, A. Delaille, H. Gualous, P. Gyan, R. Revel, J. Bernard, E. Redondo-Iglesias, and J. Peter, "Calendar aging of commercial graphite/LiFePO4 cell - Predicting capacity fade under time dependent storage conditions," Journal of Power Sources, vol. 255, pp. 450-458, 2014.

[21] M. Broussely, S. Herreyre, P. Biensan, P. Kasztejna, K. Nechev, and R. Staniewicz, "Aging mechanism in $\mathrm{Li}$ ion cells and calendar life predictions," Journal of Power Sources, vol. 97-98, pp. 13 - 21, 2001.

[22] M. Dubarry, C. Truchot, and B. Y. Liaw, "Cell degradation in commercial LiFePO4 cells with high-power and high-energy designs," Journal of Power Sources, vol. 258, pp. 408 - 419, 2014.

[23] E. Redondo-Iglesias, P. Venet, and S. Pelissier, "Eyring acceleration model for predicting calendar ageing of lithium-ion batteries," Journal of Energy Storage, vol. 13, pp. 176 - 183, 2017.

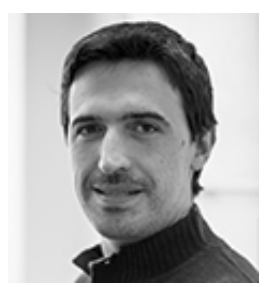

Eduardo Redondo-Iglesias was born in Vigo, Spain, in 1981. He received in 2007 the Master's Degree in Electrical Engineering from the University of Vigo.

In 2009, he joined the Transports and Environment Laboratory of the IFSTTAR in Bron, France. $\mathrm{He}$ is in charge of the battery test equipments in the LTE. His research activities are electrical modelling and characterization of batteries and their ageing for transportation applications.

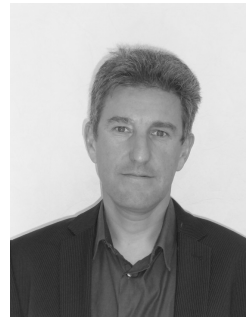

laboratory.
Pascal Venet was born in Aix-Les-Bains, France, in 1965. He received the Ph.D. degree in electrical engineering in 1993 from the Lyon 1 University, France. After postdoctoral positions, he joined the Lyon 1 University as Assistant Professor from 1995 to 2009 .

Since 2009, he has been Professor of Electrical Engineering at the Lyon 1 University. He has developed his research activity in an Electrical Engineering Laboratory (AMPERE). He is responsible for the team "Secure Systems and Energy" of the

His current research interests include characterization, modeling, fault diagnostics, reliability and ageing of energy storage systems such as batteries, supercapacitors and capacitors.

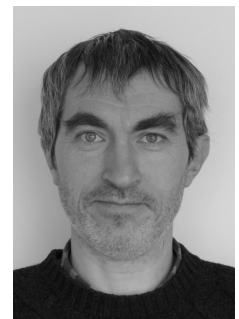

Serge Pelissier was born in 1963. He passed the agrégation of Electrical Engineering (1986) after schooling Ecole Normale Supérieure de Cachan. With a $\mathrm{PhD}$ in Electrical Engineering from the Institut National Polytechnique Grenoble, he first became Associate Professor and then Professor at the University of St. Etienne. His research focused on optical instrumentation, integrated optics as well as didactics of physics.

In 2007, he joined the Laboratory Transports and Environment at INRETS (IFSTTAR since 2011) in Bron, where he is in charge of the energy storage studies. His work focuses on modeling, characterization and aging of batteries in automotive applications. Since 2013, he is the head of the Laboratory Transports and Environment. 